\title{
AN ANALYSIS OF MODALITY IN EMMA WATSON AND MICHAEL KIMMEL'S SPEECH TEXTS
}

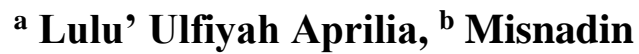 \\ ${ }^{a, b}$ Universitas Trunojoyo Madura \\ e-mail: Luluulfiyahaprilia@gmail.com
}

\begin{abstract}
This study used Palmer's (1986) theory to analyzed Modality and Halliday (2008) to analyze the meaning of modality. Relating to the statements above, this study was proposed to answer two articulated research problems, namely; (1) what are the types of modality found in Emma Watson and Michael Kimmel's Speech Texts? And (2) To what extent do Emma Watson and Michael Kimmel's Speech Texts show similarities and differences, if any, in their use of types of modality? This study employs a descriptive qualitative design. The data were all of the speech by Emma Watson and Michael Kimmel's Speech Texts that contain modality. In terms of types of modality, 30 data of modality were found. The data are classified into two types of modality: Epistemic modality consists of 10 data; judgments ( 5 data) and modifications ( 5 data). Deontic modality consists of 20 data; directives (3 data), modifications (4 data), subjectivity ( 5 data), imperatives ( 3 data), commissives ( 2 data), and volitives ( 3 data). Moreover, in terms of similarities and differences, the data are classified into two terms similarities and differences. We found 11 data of similarities and differences in types of modality: In terms of similarities in types of epistemic modality (3 data) and similarities in types of deontic modality ( 2 data). In terms of differences in epistemic modality (2 data) and differences in deontic modality (4 data).
\end{abstract}

Keywords: Modality, Epistemic, and Deontic 


\section{INTRODUCTION}

Language is the most effective and practical means of communication. One of the purposes of language is used by people to exchange information or convey their ideas and feelings such as ordering, offering, promising, etc.

According to Palmer (1979) semantic is a study instead of science which has meaning in language to do some communication with people. It investigates how people communicate meanings with smithereens of language.

Hurford (2007) states that semantic is study of meaning in language. It focuses on discovering and understanding about the real meaning of works, phrase, clause, and sentence in language. Semantics is the systematic study of meaning in linguistic (Kreidler, 1998). Therefore, semantics is crucial in ordering and delivering some information to people in our everyday communication. A communication occurs when the hearer and the speaker can understand each other.

In order to have a successful communication, factual information is needed by the speaker to provide some of the important categories of modality such as epistemic modality, and deontic modality to say that it has to do with the speaker approves towards some situation expressed in an utterance. Modality is one of the elements of semantic in linguistic aspects.

According to Portner (2008), modality is the linguistic phenomenon whereby grammar allows one to say things about. Besides that, Griffths (2006) also say that modality is the label given the meaning includes obligation to make situation come about, indications of whether or not it is permissible feasible and also included are signal as to how confident the speaker is regarding knowledge of the situations. In this section, we focus on the types of modality because it is more central to our understanding of modality generally and to find the similarities and differences of types modality used by Watson and Kimmel's speech texts.

Palmer (1986) divides modality into two types; those are epistemic and deontic modality. The characteristics of communication that important for people are to easily identify modality in the utterance, to have a successful communication, and also to show the logic utterance. As illustration see the following example:

(a) "You should see a doctor." (Modality)

The sentence (a) said "You should try to see a doctor." The modal verb "should" is used in deontic modality to give information and deliver her/his belief and to ask someone to go to the doctor. Modality uses modal verb, such as must, can, may should, how to, it is possible to, which is used to each type of modality.

We are interested in analyzing modality because sometimes people do not realize when they use modality in their speeches and when they want to deliver some information, knowledge, obligation, giving and asking permission by using modal verb to other people in their daily conversation. Therefore, modality is very important to know and use in daily life.

We elaborate speech texts delivered by Emma Watson and Michael Kimmel because they are the famous people in United States. The first speech text is carried out in UN Women event. In addition, Watson is one of the Ambassadors in United States. The reason why we analyze video by Watson (2014) Women He for She at UN because the content of her speech is great. In analyzing the speech texts of Emma Watson, we use full transcript text by Ekladata (2014). The second speech a text is carried out in Kimmel (2015) Why Gender Equality is Good for Everyone by Michael 
Kimmel. He is one of the influencer of gender equality and as the lecturer of sociology of Gender which delivers his speech in TED. The reason why we analyze his speech text because the content of the speech is high value related to gender equality.

The theory that we used to analyze modality in Emma Watson and Michael Kimmel's speech texts is Modality by Palmer (1986). Previous studies had been conducted by Tran Phuc Huu (2016) who analyzed modality in English corpus. He used the theory of modality by Corpora (LOB and F-LOB), claiming that "the English modal auxiliaries as a group have been declining significantly in their frequency of use" (2003:223). Another researcher is Xi Wang (2014) analyzed modality in title The Mood and Modality in The Bible: A Systematic Functional Perspective. He used the theory of Halliday (2008).

\section{METHODS}

In this study, we employed descriptive qualitative research because this study analyzed speech texts. Following Bogdan \& Biklen (1982) states about qualitative research, it states "Qualitative research is descriptive. The data is collected in the form of words or pictures rather than numbers." We used two speech videos entitled Women He for She at UN by Emma Watson released on September 22th, 2014 and Why Gender Equality is Good for Everyone by Michael Kimmel released on September 16, 2015 ${ }^{\text {th }}$. The data were uttered by Watson and Kimmel in their speech texts that contained modality.

In collecting the data we used content analysis method by Kothari (2004). The process of the collecting the data was through some steps to get better understanding of this study. First, we started by watching videos for several times to understand about the content of the videos. Then we identified all the utterances that were uttered by speakers in Women He for She at UN by Emma Watson and Why Gender Equality is good for everyone by Michael Kimmels' speech texts. To make it is easier to identify the utterances, we used modality script as guideline and transcribed all of the data. After that, all the data found were transcribed. Finally, we classified the types of modality and the distinction of modality in two videos based on the theory of Modality by Palmer 1986.

The data analyzed into some steps based on the theory of Miles and Huberman (1994) above. The first, data collection means we collected the data based on the statement of the research problems. The second, data reduction means the data were collected and selected based on the statement of the research problems. Then we typed the data into the table which were made to classify the data and to know the whole numbers of the data provided in the research.

The third, data display means we explained more the data in discussion based on the types of modality. The last, conclusion drawing/verification means we explained based on the result of the data analysis in conclusion and provide some suggestions. 


\section{FINDINGS AND DISCUSSION FINDINGS}

There are two research problems that addressed in this research. The first problem asked about types of modality and the second problem asked about similarities and differences type of modality used by Watson and Kimmel in their speech texts. Based on the first problem, we found thirty data of modality that consist of ten data of epistemic modality and twenty data of deontic modality. The table 1 provides the types of modality found in the data. The following data is below:

Table 1 Types of Modality in Emma Watson and Michael Kimmel

\begin{tabular}{|c|c|c|c|}
\hline NO & Types of Modality & Elements & Frequency \\
\hline \multirow[t]{2}{*}{1} & \multirow[t]{2}{*}{ Epistemic Modality } & Judgments & 5 \\
\hline & & Modifications & 5 \\
\hline \multirow[t]{6}{*}{2} & \multirow[t]{6}{*}{ Deontic Modality } & Directives & 3 \\
\hline & & Modifications & 4 \\
\hline & & Subjectivity & 5 \\
\hline & & Imperatives & 3 \\
\hline & & Commissives & 2 \\
\hline & & Volitives & 3 \\
\hline \multicolumn{3}{|c|}{ TOTAL } & 30 \\
\hline
\end{tabular}

Table 2 shows similarities and differences in types of modality used by Watson and Kimmel. In general people people have their own characteristic in delivering their speech texts. There are 11 data of similarities and differences type of modality found in Watson and Kimmel's speech texts. The subsequent data is below.

Table 2 Similarities and Differences in types of modality used by Watson and Kimmel

\begin{tabular}{|l|c|c|c|}
\hline \multicolumn{1}{|c|}{ Aspects } & Epistemic & Deontic & Frequency \\
\hline $\begin{array}{l}\text { Similarities } \\
\text { Watson \& Kimmel }\end{array}$ & 3 & 2 & 5 \\
\hline $\begin{array}{l}\text { Differences } \\
\text { Watson \& Kimmel }\end{array}$ & 2 & 4 & 6 \\
\hline \multicolumn{2}{|c|}{ Total } & 11 \\
\hline
\end{tabular}

\section{DISCUSSION}

The following discussion are structured as followed. Into point 1 we are going to discuss about epistemic modality, point 2 we are going to elaborate about deontic modality and point 3 we are going to explain about similarities and differences type of modality in Watson and Kimmel's speech texts.

\section{Types of Modality}

Palmer (1986) defines modality as a system of modal verbs: will, can, may, must, should, would, could, might, have to, had to, and ought to. Modality is a semantic term used to refer to the meanings of modals. We can understand the statement which is delivered by people in the modal auxiliary of their speeches. He divides modality into two types, epistemic and deontic modality. 


\section{Epistemic Modality}

Epistemic is concerned with the speaker's evaluation/judgement of, degree of convidence, or belief in, the knowledge upon which a proposition of an utterance is based. Various degree of commitment from an epistemic scale going from certainty that a state of affairs applies to certainty that it does not apply, via a neutral stance towards its occurance (Nuyst 2001:21-22). Palmer (1986) divides epistemic modality into two types: Judgments and Modifications. Below is the example of epistemic modality in Emma Watson and Michael Kimmel's speech texts.

\subsection{Judgments}

In language, it is possible to have kinds of epistemic judgments; strong judgments and weak judgments. These specified judgments are involved in modal verb may and must. It can be contemplated first.

\section{a. May and Must}

There are two possible approaches which show the distinction of these verbs. First, the relation between them can be clearly stated in the terms of possibility and necessity. The possibility can be stated as the modal verb may. The example is below

They may not know it, but they are inadvertent feminists that changing the world today.

A modal verb may not is epistemic modality because the speaker delivers his knowledge and information to the audiences. May is able to be categorized as judgments. In terms of negative judgments, it is positive proposition and in terms of negation, it is positive judgments. The statement "It is certain that they do not know it, but they are inadvertent feminists that changing the world today means that eventhought her parents and her mentors are impossible to recognize about gender equality but they are unintentional feminist changing the world. In terms of meaning it has negative and in terms of probability, it has high value because it is possible to happen.

\section{b. Will}

Another kind of judgments is will. This is because English is not only having two kinds of epistemic modality. The modal verb will as a reasonable judgment, may indicates possible judgments and must is the only possible judgment. Will falls between weak judgments may and strong judgment must. Modal verb will is also used in such a sentence:

Feminism will make possible for first time for men to be free.

The modal verb in the sentence above involving epistemic modality is will. It's because the speaker delivers his belief and knowledge about feminism. Will can be categorized as Judgments because the speaker gives a reasonable judgment to the audiences that feminism gives a positive impact for men to be free. Therefore, they could not work so hard to collect money and they are able to keep their healthy, their body than before. From this statement 'Feminism is probable to make possible for first time for men to be free' we can identify that Kimmel believes feminism gives more advantages for men to be free than for women. It is because women help men to work. 
The modal verb will in this statement in terms of meaning, it is positive and in terms of probability, it is low value because the speaker used will to make sure his belief to the audiences that it is possible to happen.

\subsection{Modifications}

Modifications is one of the types of epistemic modality. According to Palmer (1986) English has modifications to modify three types of judgments (may (can)/must and will). It has what might be called as tentative (Palmer, 1979b: 48-50) which are formally past tense forms, i.e. might and would (I'd).

\section{But why should we support gender equality?}

The modal verb should in this context can be classified as epistemic modality because the speaker delivers his strong question to the audiences by using the modal verb should. This question is answered by him self that "Of course, it's fair, it's right, and it's just". The modal verb should has a similarity in meaning to the modal verb must.

This statement "But why we are supposed to support gender equality?" can be interpreted as the speaker gives a question used modal verb should in order to give a strong judgments to the audiences about why we are considered to support gender equality? By this strong judgment, the hearer or the audiences will realize how gender equality is crucial to be applied in our daily life. In terms of meaning, should is positive because it is possible and in terms of obligation, it is medium value because it is not possible to happen.

\section{Deontic Modality}

According to Lyons (1977:83) deontic modality is concerned with the necessity and possibility of acts performed by morally responsible agent. 'Deontic' is used in a wide sense include in this type of modality that are characterized by Jespersen (1990). Meanwhile Palmer (1986; 96), deontic modality is concerned with action, by other and by the speaker himself. Deontic modality relates to obligation and permission. There are six elements of deontic modality; Directives, Modifications, Subjectivity, Imperatives, Commissives and Volitives.

\subsection{Directives}

Palmer (1986) said that Must and May are important in deontic modality as giving permission. Therefore it would be better to talk about directives is when we try to get initiating action from the hearer to do things.

\section{a. May/Must}

May and Must as English have a basic degree called as 'weak' and 'strong' (Palmer, 1986). In deontic modality May/can is used for giving permission and Must is used for laying an obligation to the hearer.

If we stop defining each other by who we are not and start defining ourselves by who we are, we can all be freer and this is what HeforShe is about. 
The modal verb can can be categorized as deontic modality because it is concerned with action, by other and the speaker himself. Deontic modality relates to obligation and permission. The sentence above is directive because the modal verb can is similar to May for giving permission. It is merely presented as a deontic 'proposition' and the meaning of may/can is deontic possibility. The hearer is left to force his obligation to act from the circumstances. The statement above can be interpreted as 'If we stop defining each other by who we are not, and start defining ourselves by who we are, we are possible to be freer. And this is what HeforShe is about". In terms of meaning, the modal verb may/must has positive and in terms of probability, it has low value because it is possible to happen.

\section{b. Modifications}

Palmer (1986) modifications in deontic modality is used to modify language that have similarly related forms. It is different with epistemic modality which is used tentative forms: Must has ought to/should, may has might (or can, could).

\section{I had to start thinking about them. And it had been privilege that had} kept it invisible to me for so long.

The modal verb had to in the data above can be categorized as deontic modality because the speaker delivers an obligation statement to allow the audiences to start thinking about his friends (white and black women) which are talking about privilege. $\mathrm{Had}$ to is modifications of modal verb must and it has meaning of obligation (necessary/require) because it refers to past event and it may be fulfilled. Therefore, the sentence can be analyzed as 'I am necessary/I require to start thinking about them, or I have an obligation to start thinking about them. From the statement above, we can analyze that the speaker uses modification of must in order to ask or commit himself and influences the audiences to start thinking about privilege is invisible to him for so long. In terms of meaning, it has positive and in terms of obligation, it has high value because it is possible to happen.

\section{c. Subjectivity}

Subjectivity is the important features of modality (Palmer, 1986). It is subjectoriented which to be concerned as the permission about ability and willingness of the subject. Can and will are the modal verbs subject-oriented used in subjectivity.

Except for my son, who said "Well, he could have two dads."

The next modal verb is Could. It can be classified as subjectivity in types of deontic modality because the speaker told his son's answer to the audiences about giving permission that the child has an ability to have two dads. From the data above, it can be analyzed as 'Well, he has ability/ he is possible to have two dads'. This statement means that his child ask permission to him to show the ability of the son that he could have two dads. In terms of meaning, it has positive meaning and in terms of probability it has low value because it is possible to happen. 


\subsection{Imperatives}

Imperatives is one of the types of deontic modality that has a simple form (Palmer, 1986). Imperatives is not as strong like modal verb must and may because it just shows as a deontic 'proposition', and the hearer left to judge the force of the obligation. Imperatives consist of commanding, inviting and also requesting.

I invite you to step forward, to be seen and ask yourself, "if not me, who? If not now, when?

The word invite above shows deontic modality because the speaker invites the audiences to step forward to apply gender equality in their life. The sentence above can be categorized as imperative sentences because the speaker asks the audiences presented deontic 'proposition'. This statement can be interpreted as 'It is necessary that you must step forward, to be seen and ask yourself, if not me who? If not now, when?' because the speaker asks the audiences by using the word "invite" to be seen who and when they want to change this world in accepting gender equality. In terms of meaning, must has positive and in terms of obligation, it has high value because it is possible to happen.

\subsection{Commissives}

Searle (1969) defined commissives as when we commit ourselves to do things as like promises and threats and the only difference between these what the hearer wants). This type uses modal verb shall.

Both men and women should feel free to be strong.

The next modal verb in the sentence above is Should. Should in this context is deontic modality because it relates to obligation and permission. Should is commissives because the speaker commits everyone in the world and especially for the audiences that men and women should feel free to be strong. This statement 'both men and women are supposed to feel free to be strong' means that the speaker delivers an obligation to the audiences between men and women based on gender equality. In terms of meaning should has positive and in terms of obligation, it has median value because it is possible and possible not to happen.

\subsection{Volitives}

Volitives is the type of deontic modality which expresses the subordinate clauses the grammatical distinction between hopes and wishes in the same way as that real or unreal conditional (Palmer, 1986).

If not me, who? If not now, when? If you have similar doubts and opportunities are presented to you, I hope those words will be helpful.

The lexical verb hope in the statement above is included in type of deontic modality because it is concerned more with possible action than the truth. Hope is volitives because the speaker specifies the desires, wishes or fears to the audiences that he wants to make all the audiences understand the deepest meaning of those words. This volitives is deontic modals and concern more with possible action than with the truth. There are two lexical items used in volitives are wish and hope. 
This statement 'If not me, who? If not now, when? If you have similar doubts and opportunities are presented to you, I hope those words are probable to be helpful.' can be interpreted as the speaker desires to share the meaning of the words that she has delivered to the audiences. The speaker hopes those words will be helpful because she absolutely understands what is going to be happen if we still do not care about gender equality. Therefore, she wants the audiences to understand and apply gender equality in their life. Sometimes, volitives is followed by modal verb will. In terms of meaning this modal verb is positive because it is possible to happen and in terms of probability is medium value because it is not possible to happen.

\section{The Similarities and Differences in Types of Modality Used by Emma Watson and Michael Kimmel}

In every speech we can find some similarities and differences between one speaker and another speaker to deliver their idea, knowledge and belief. In this research, we analyze the similarities and differences between two speakers delivered their speech about gender equality or feminism.

\subsection{Similarities in Types of Epistemic and Deontic Modality Found in Watson and Kimmel's Speech texts.}

In analyzing the similarities, we compare all the data found in analysis of the first research problem between Watson and Kimmel's speech texts. The following data is below:

\subsubsection{Similarities in Types of Epistemic Modality Found in Watson and Kimmel's Speech texts.}

The first data of similarities that we found in Watson and Kimmel speech texts is Watson and Kimmel deliver speeches about feminism based on the story of their life by using modal verb will. In order to show the fact or give information to the audiences that it is real. It can be conclude that the speakers used the modal verb in past time.

We provide the texts that show Watson and Kimmel deliver a speech based on the story of their life. Watson's speech text: Because They may not know it but they are inadvertent feminist that change my life today. Kimmel's speech text: I would pose this riddle to them.

As we can see from the example above that Watson realizes as a women we must be involved on our behalf and be justice to make decision in our life. Watson tells to the audience that she really proud to her mentors, parents and friends that thought her everything relate to feminism even they do not realize that it changes her life. This statement shows that the speaker understands how gender equality affects to her life because the experience that forces her to be wise in making decision. Besides, Kimmel also shows how he as man attempts to understand what feminism is because he believes that feminism gives an advantage for men to be free. Based on the story that he wants to pose this riddle to his son relate to gender equality.

\subsubsection{Similarities in Types of Deontic Modality Found in Watson and Kimmel's Speech texts.}

The first data Watson and Kimmel use Imperatives sentences by using proposition in their speech texts. Based on our analysis, Watson and Kimmel use imperatives sentence by using proposition in imperatives sentence. They use imperatives sentence in order to command, invite ask and request to the audience to 
follow their argument relate to gender equality or feminism. We analyze that speech texts are belong to imperative sentence can be categorized as the word invite, ask, command, request, and inclination word or stop.

The speakers use imperative sentence. We provide speech texts that show Watson and Kimmel use Imperative sentences by using proposition in their speech texts. Watson's speech text: Reclaim those parts of themselves they abandoned and in doing so be a more true and complete version of themselves. Kimmel's speech text: Look! We think this is a level playing field so any policy that tilts it even a little bit we think "OMG waters rashing uphill" it reverses discrimination againts us.

From the statement above, we can analyze that Watson tries to demand the male to eliminate gender discrimination and to support feminism. Furthermore, Kimmel tries to ask the audiences to give their attention to the illustration how men reverse a discrimination of gender equality.

\subsection{Differences in Types of Epistemic and Deontic Modality Found in Watson and Kimmel's Speech texts}

In analyzing the differences, we compare all the data which are found in analysis of the first research problem between Watson and Kimmel's speech texts.

\subsubsection{Differences in Types of Epistemic Modality Found in Watson and Kimmel's Speech texts}

The first data of differences in type of epistemic modality is Watson uses epistemic modality to emphasize knowledge how gender equality or feminism is important to be applied in this world especially for women's welfare. Moreover, Kimmel uses epistemic modality to explain that gender equality or feminism gives more advantage to men.

We provide the speech texts that show Watson used epistemic modality to give knowledge how gender equality or feminism is important to be applied in this world and Kimmel used deontic modality to explain that gender equality or feminism gives more advantages to men. Watson's speech texts: Because the reality is that if we do nothing, it will take seventy five years, or me to be nearly 100, before women can expect to be paid the same as men for the same work. 15.5 million Girls will be married in the next 16 years as children. And the current rates, it won't be until 2086 before all rural African girls can have a secondary education. Kimmel's speech texts: Feminism will make possible for first time for men to be free. Now, I will say just to remind the men in the audience.

From the statement above, we can analyze that the speakers have different purpose of feminism in their speech. Watson tried to elaborate disadvantages and the advantages about life without gender equality for women. Moreover, Kimmel attempts to elaborate the advantage of applying gender equality for men.

\subsubsection{Differences in Types of Deontic Modality Found in Watson and Kimmel's Speech Texts}

The first data is Watson tends to use commissives than subjectivity and Kimmel tends to use subjectivity than commissives. We provide the example that Watson tends to use commissives than subjectivity and Kimmel tends to use subjectivity than commissives. Watson's speech texts: For the record, feminism by definition is the belief that men and women should have equal rights and opportunities. I think it is right that I should be able to make decision about my own body. Both men and women 
should feel free to be strong. Kimmel's speech texts: Except for my son, who said "Well, he could have two dads." What could be a better signifier of disembodied Western rationality?

From the statement above, we can identify that Watson really expect and persuade the audiences to do what she said. She commits all the audiences to step forward to be seen how gender equality or feminism is really important for us especially to change the life of women tradition. Watson uses commissives 3 times than Kimmel. Kimmel often uses subjectivity in his speech than commissives because he wants to take permission to show an ability of some people in his speech to the audiences relate to gender equality for men. However, there are 2 data of subjectivity found in Kimmel and 1 data found in Watson. Therefore, it can be classified that Kimmel does not use commissives in his speech texts.

\section{CONCLUSION}

This research is aimed to identify and find out both the types of modality and similarities and differences used by Emma Watson and Michael Kimmel's speech texts. We found 36 data from two sources of data which are included as the items of types of modality. In analyzing the types of modality we used theory proposed by Palmer (1986) which is divided into two types epistemic modality and deontic modality. We found 30 data modality in Emma Watson and Michael Kimmel's speech texts that consist of 10 data of epistemic modality; 5 data belong to judgments and 5 data belong to modifications and 20 data of deontic modality; 3 data belong to directives, 4 data belong to modifications, 5 data belong to subjectivity, 3 data belong to imperatives, 2 data belong to commissives, and 3 data belongs to volitives.

Moreover, analyzing types of modality, we used the theory of meaning of modality proposed by Halliday (2008:147). The meaning of modality is Probability, Usuality, Obligation and Inclination. Relating to this theory, we analyzed the meaning of each types of modality found in Watson and Kimmel. Meanwhile, analyzing types and meaning of modality, we tried to discover the similarities and differences in types of modality used by Watson and Kimmel's speech texts. Relating to this analysis, we found 11 data of similarities and differences in types of epistemic and deontic modality; 5 data of similarities in types of epistemic and deontic modality and 6 data of differences in types of epistemic and deontic modality used by Watson and Kimmel's speech texts. As a result, men tends to use epistemic modality and women tends to use deontic modality in their speech texts.

\section{REFERENCES}

Bogdan, R. C. (1982). Qualitative Research for Education: An Introduction to Theory and Method. Massachusetts: Allyn and Bacon, Inc.

Ekladata. (2014). Full Transcript of Emma Watson's Speech on Gender Equality at the UN. Full Transcript of Emma Watson, 1-2.

Griffiths, P. (2006). Modality. In P. Griffiths, An Introduction to English Semantics and Pragmatics (p. 111). Edinburgh: Edinburgh University Press.

Halliday. (2008). Meaning of Modality. Epistemic Modality and Deontic Modality Two sides of A Coin, 162-167. 
Hurford, H. S. (2007). Semantics A Coursebook Second Edition .USA: Cambridge University Press.

Huu, T. P. (2016). Analyzing Modality Expression as hedges in English Corpus

Jespersen, O. (1924:). Deontic Modality. In F. Palmer, Mood and Modality (p. 96). Cambridge: Cambridge University Press.

Kimmel, M. (2015, September 16). Why Gender Equality is Good for Everyone. Retrieved from Why Gender Equality is Good for: https://www.ted.com/talks/michael_kimmel_why_gender_equality_is_good_fo r_everyone_men_include/up-next

Kothari, C. R. (2004). Research Methodology: Method \& Techniques. New Delhi: Publisher

Kreidler, C. W. (1998). Introducing Engish Semantics. London and New York: Routledge.

Lyons, J. (1977). Deontic. In Palmer, Mood and Modality (p. 18). Cambridge: Cambridge University Press.

Miles, M. B. (1994). Qualitative Data Analysis: Thousand Oaks. CA: Sage.

Nuyst, J. (2001a) Epistemic Modality, Language and Conceptualization. (2001). In P. Portner, Modality and Mood (p. 123). USA: Georgetown University.

Palmer, F.R. (1986). Mood and Modality . Cambridge: Cambridge University Press.

Palmer, F.R. (1979). Semantics Second Edition . Britain: Cambridge University Press.

Portner, P. (2008). Modality. USA: Georgetown University

Searle. J. R. (1969). Speech Acts: An Essay in the Philosophy of Language. Cambridge University Press.

Sugiyono. (2009). Metode Penelitian Kuantitatif dan Kualitatif dan R \& D. . Bandung: Alfabeta.

Wang, X. (2014). The Mood Modality in Bible: A Systemic Functional Prespective. The Mood and Modality in the Bible: A Systemic Functional Perspective, 4(2) 1-7.

Watson, E. (2014, September 24). Emma Watson at the HeForShe Campaign 2014 Official UN Video. Retrieved from Emma Watson at the HeForShe Campaign 2014 https://www.youtube.com/watch?v=Q0Dg226G2Z8 